\title{
Audit of continuing medical education for pathologists: strategies and implications
}

\author{
C du Boulay
}

\section{Royal College of Pathologists (RCPath) CME programme}

The RCPath has decided to implement continuing medical education (CME) for all pathologists in the UK, starting with a pilot study in Wessex. There are three parts to this scheme: (1) acquisition of CME credits; (2) paired peer review; and (3) use of distance learning packages.

The Wessex pilot started in April 1994, with the implementation of paired peer review and CME credits. In April 1995 the CME credit scheme was started nationally.

\section{Introduction}

Continuing medical education, or continuing professional development, is a process which should extend from qualification to retirement. It enables all those in health care professions to enhance their performance and careers, to maintain high standards of patient care and to acquire new expertise, adopt new roles, and manage change. ${ }^{1}$ The performance, accountability and education of doctors is now in the public domain. CME should concentrate on individuals' needs but at the same time should take account of the wider context of health care provision. Many groups have a stake in effective CME, including patients, NHS managers and trusts, universities, and Royal Colleges.

\section{Why evaluate?}

There is no doubt that CME is expensive and time consuming; doctors need time for study, reflection and to attend learning courses. ${ }^{2}$ In order to identify the problems and effectiveness of CME, we need to evaluate the process and its outcomes in order to justify the time and expense, and modify these where necessary so that pathologists remain not just competent, but are continually improving their practice. ${ }^{3}$

However, methods of doing this are not well developed and will be as expensive and time consuming as CME itself. Criteria for "effective" CME have been described ${ }^{4}$ and any evaluation of the CME process should address the following questions ${ }^{1}$ :

Department of Pathology, Mail point 813, Level E, South Pathology Block, Southampton General Hospital, Southampton SOuthamp C du Boulay
- Is the system flexible enough to meet present and future needs?

- Is it accessible to both the highly motivated and the average performer?

- Are there mechanisms to ensure that CME is responsive to the corporate needs of the NHS?

- Is performance improved for all doctors in the system and how does the number of poor performers relate to use of the scheme?
- What training inputs are required?

- How much time is needed for the process of reflection, appraisal, planning, and personal review?

- What is the impact on departments and trusts in terms of study leave requirements?

- How can the outcomes be measured?

\section{What is educational evaluation?}

Evaluation represents an attempt to identify and interpret the effects and effectiveness of teaching and learning. Gathering information about an educational programme or process enables us to make judgements about its merit. ${ }^{5}$ This should lead to improvements in future teaching and the alteration of educational formats in response to consumer demand. The cycle of educational evaluation is analogous to clinical audit whereby "completion of the loop" leads to changes and improvements in practice.

Different methods and models of evaluation can be combined to give the most complete and accurate picture. ${ }^{6}$ Whenever and however it is done, the evaluation process should be useful, feasible, appropriate, and accurate. ${ }^{7}$

\section{MODELS OF EVALUATION}

In its simplest form, evaluation measures whether an educational event has met its aims and objectives and delivered a satisfactory outcome-that is, most of the students at the end of a course will pass the examination. ${ }^{5}$ A more sophisticated approach acknowledges that the learners' expectations, the educational event and the eventual changes in behaviour (outcomes) are inextricably linked. This input, content and process model is widely used. ${ }^{8}$

A more descriptive kind of evaluation is the "illuminative view", which is likened to shining torches on the problem. The more torches which are held from more angles, the more light will be shed. ${ }^{9}$ Responsive evaluation involves all those who have an interest in the educational process taking part. ${ }^{10}$

The hierarchical model of educational evaluation starts with measurements of participant satisfaction and progresses through to measurement of actual learning, transfer of learning to the workplace and ultimately the impact on the community at large. It is evaluation of these outcomes which is so difficult to do and which will be the cornerstone of CME evaluation. ${ }^{8}$

\section{How to evaluate?}

There is a wide range of evaluation methods available. They are either qualitative or quant- 
itative and any combination can be used. ${ }^{6}$ Qualitative methods include interviews, observation and experiential techniques. Quantitative methods involve the use of questionnaires, rating scales and observation schedules. Quantitative methods have the advantage that reliable and objective "hard" data are produced, whereas qualitative methods, such as interviews, produce more descriptive data which can give deeper insight into a process such as CME..$^{1112}$

\section{Implications of evaluation of CME}

Pathologists all over the country are beginning to collect their CME credits. Most pathologists in Wessex are also participating in a pilot paired peer review scheme, which will be evaluated locally. We must begin to think about how to evaluate our CME and what outcomes we want to measure. There are a number of stakeholders who will be interested in the findings. These include Royal College of Pathologists, Regional education committees, College tutors, participants, and NHS trust managers. If CME can be justified and shown to be effective, the training needs of pathologists will need to be built into trust business plans. We need to recognise that there is often a tension between educational wants and needs. Although educational desires are driven by personal choice and experience, there should be a balance between the needs of the individual and those of the organisation. ${ }^{13}$

The wider issues which surround CME are important and have political overtones. Already in the USA and Australia, CME is being used as a measure of competence and as a basis for re-certification for practice. Evaluation will be important if there are going to be concerns with re-accreditation issues and advice to NHS trusts about poor performers.
The important questions which need answering are: does CME improve clinical performance and is it worth paying for? There is still doubt about whether CME really does improve clinical practice. ${ }^{14}$ There are so many variables that it may not be worth trying to document whether a single event changes behaviour. ${ }^{1516}$ In order to meet the objectives for CME evaluation proposed by the Standing Committee on Postgraduate Medical Education, ${ }^{1}$ long term evaluation with measurement of second order outcomes must be carried out. This raises two important questions: who should do this and who will pay?

1 Standing Committee on Postgraduate Medical Education. Working paper. Continuing professional development for doctors and dentists. London: Standing Committee on Postgraduate Medical Education, 1994.

2 Anonymous. Continuing medical education [editorial]. Lancet 1993;342:1497-8.

3 Beaudry JS. The effectiveness of CME: a quantitative synthesis. Fournal of Continuing Medical Education in the Health Professions 1989;9:285-307.

4 Harden RM, Laidlaw JM. Effective continuing education: the CRISIS criteria. Med Educ 1992;26:408-22.

5 Coles CR, Grant JG. Curriculum evaluation in medical and health care evaluation. Med Educ 1985;19:405-22.

6 Irby DM. Evaluating instruction in medical education. fournal of Medical Education 1983;58:844-9.

7 Edwards J. Evaluation in further education: a practical handbook for teachers and organisers. Liverpool: WEA, 1991.

8 Pitts J, Percy D, Coles C. Evaluating teaching. Education for General Practice 1995;6:13-18.

9 Norris N. Understanding educational evaluation. London: Kogan Page, 1990.

10 Guba EG, Lincoln YS. Effective evaluation: improving the usefulness of evaluation results through responsive and naturalistic approaches. San Francisco: Jossey Bass, 1981.

11 Hycner RH. Some guidelines for the phenomenological analysis of interviews. Human Studies 1985;8:279-303.

12 Loffland J, Loffland L. Analyzing social settings: a guide to qualitative observation and analysis. London: Wadsworth, 1984.

13 Jayawickramarajah PT. How to evaluate educational programmes in the health professions. Med Teach 1992;14: 159-66.

14 Davidoff F, Haynes B, Sackett D, Smith R. Evidence based medicine. BMF 1995;310:1085-6.

15 McLaughlin PA, Donaldson JF. Evaluation of CME programs; a selected literature. Fournal of Continuing Medical Education in the Health Professions 1992;11:65-84.

16 Davis DA, Thomson MA, Oxman AD, Haynes B. Evidence for effectiveness of CME. $\mathcal{F A M A}$ 1992;268:1111-17. 